\section{(1) \\ CrossMark}

\title{
Future trends in cystic fibrosis demography in 34 European countries
}

\author{
Pierre-Régis Burgel ${ }^{1,2,9}$, Gil Bellis ${ }^{3,9}$, Hanne V. Olesen ${ }^{4}$, Laura Viviani ${ }^{5}$, \\ Anna Zolin ${ }^{5}$, Francesco Blasi ${ }^{6}$ and J. Stuart Elborn ${ }^{7,8}$ on behalf of the ERS/ECFS \\ Task Force on The Provision of Care for Adults with Cystic Fibrosis in Europe ${ }^{10}$
}

Affiliations: ${ }^{1}$ Cochin Hospital, Assistance Publique Hôpitaux de Paris, Paris, France. ${ }^{2}$ Université Paris Descartes, Sorbonne Paris Cité, Paris, France. ${ }^{3}$ Institut National d'Etudes Démographiques, Paris, France. ${ }^{4}$ CF Centre Skejby, Aarhus University Hospital, Aarhus, Denmark. ${ }^{5}$ Dept of Clinical Sciences and Community Health, University of Milan, Milan, Italy. ${ }^{6}$ Dept of Pathophysiology and Transplantation, Università degli Studi di Milano, IRCCS Fondazione Ca' Granda, Ospedale Maggiore Policlinico, Milan, Italy. ${ }^{7} \mathrm{CF}$ and Airways Microbiology Group, Queen's University Belfast, Belfast, UK. ${ }^{8}$ Centre for Infection and Immunity, School of Medicine, Dentistry and Biomedical Sciences, Queen's University Belfast, Belfast, UK. ${ }^{9}$ Both authors contributed equally. ${ }^{10} \mathrm{~A}$ list of the Task Force members can be found in the Acknowledgements section.

Correspondence: Pierre-Régis Burgel, Service de Pneumologie, Hôpital Cochin, 27 rue du Faubourg St Jacques 75014 Paris, France. E-mail: pierre-regis.burgeldcch.aphp.fr

ABSTRACT Median survival has increased in people with cystic fibrosis (CF) during the past six decades, which has led to an increased number of adults with CF. The future impact of changes in $\mathrm{CF}$ demographics has not been evaluated. The aim of this study was to estimate the number of children and adults with CF in 34 European countries by 2025.

Data were obtained from the European Cystic Fibrosis Society Patient Registry. Population forecasts were performed for countries that have extensive CF population coverage and at least 4 years of longitudinal data by modelling future entering and exiting flows in registry cohorts. For the other countries, population projections were performed based on assumptions from knowledge of current CF epidemiology.

Western European countries' forecasts indicate that an increase in the overall number of CF patients by 2025 , by approximately $50 \%$, corresponds to an increase by $20 \%$ and by $75 \%$ in children and adults, respectively. In Eastern European countries the projections suggest a predominant increase in the CF child population, although the CF adult population would also increase.

It was concluded that a large increase in the adult $\mathrm{CF}$ population is expected in the next decade. A significant increase in adult CF services throughout Europe is urgently required.

@ERSpublications

A large increase in the number of CF adults is expected by 2025 that will require increase in adult CF care services http://ow.ly/INkvb

Editorial comment in Eur Respir J 2015; 46: 11-12 [DOI: 10.1183/09031936.00026615]

This article has supplementary material available from erj.ersjournals.com

Received: Oct 232014 | Accepted after revision: Jan 262015 | First published online: March 182015

Conflict of interest: Disclosures can be found alongside the online version of this article at erj.ersjournals.com 


\section{Introduction}

Cystic fibrosis (CF) is a genetic multiorgan disease characterised by predominant pulmonary involvement, leading to respiratory failure and premature death [1]. Over the past six decades, an impressive improvement in survival has been achieved by antibiotic therapy, mucoactive drugs, optimisation of nutrition through pancreatic enzyme replacement and the implementation of multidisciplinary care, initially in CF centres for children and more recently in centres providing care for CF adults [2].

Recent studies explored the current epidemiology of CF in Europe. FARreLL [3] estimated the prevalence of $\mathrm{CF}$ in European Union (EU) countries, while McCовміск et al. [4] and MeнтA et al. [5] provided cross-sectional data on demographics of $\mathrm{CF}$ in EU and non-EU countries. The increased survival in CF patients resulted in the number of adults (age $\geqslant 18$ years) with CF being larger than the number of children in several EU countries with well-established healthcare systems $[4,6]$. In many non-EU countries, where allocation of resource to healthcare is lower, survival has also improved but the numbers of CF adults are still lower than those of CF children [4]. Although these data shed light on changing epidemiology of CF, the impact of prolonged survival on future numbers of CF adults has not been evaluated.

In 2012, the European Respiratory Society and the European Cystic Fibrosis Society (ECFS) formed a Task Force on The Provision of Care for Adults with CF in Europe. One of the goals of this task force was to estimate the numbers of CF children and adults in most European countries (irrespective of their EU membership) by 2025. The rationale behind this goal was to inform on future CF demographic trends across European countries and to plan an adequate development of CF care services for children and adult CF patients in each country.

\section{Methods}

\section{Sources of data and categorisation of countries}

Demographic data were obtained from the ECFS Patient Registry [6] and from the Population Reference Bureau [7], and gross national incomes (GNIs) per capita in current international dollars (\$) were obtained from the World Bank [8]. According to availability of longitudinal data (i.e. data linked across the years at individual patient level) in the ECFS Patient Registry, coverage of their national CF population and GNIs per capita, 34 European countries were grouped into four groups (A, B, C and D) (table 1).

Group A included countries contributing data to the ECFS Patient Registry, with a coverage of their national $\mathrm{CF}$ population $\geqslant 85 \%$ and with longitudinal data for at least 4 years. These countries included Belgium, Czech Republic, Denmark, France, UK and the Netherlands.

Group B included countries contributing data to the ECFS Patient Registry, with coverage of their national $\mathrm{CF}$ population $\geqslant 85 \%$, but without longitudinal data for at least 4 years. These countries included Germany, Hungary, Ireland, Israel, Latvia, Moldova, Serbia, Sweden, Slovenia and Slovakia. Although Hungary reported population coverage $\geqslant 85 \%$ and longitudinal data for more than 4 years, it was included in group B (rather than A) because there was intermittent reporting of the number of deaths between 2007 and 2010, precluding reliable calculation of yearly death rates. Slovenia, which had $75 \%$ coverage, was also included in B countries because registry data appeared more reliable than calculation of patient numbers using prevalence data.

Countries that had registry coverage of their national CF population $<85 \%$ (coverage was usually in the $20-40 \%$ range) or had no data available in the ECFS Patient Registry were grouped according to their GNI per capita: countries with GNIs per capita $\geqslant \$ 23000$ (Austria, Switzerland, Cyprus, Spain, Finland, Greece, Italy, Luxemburg, Malta and Portugal) were included in group C; and countries with GNIs per capita $<\$ 23000$ (Bulgaria, Belarus, Estonia, Lithuania, Poland, Romania, Russian Federation, Ukraine) were included in group D.

\section{Computation of age composition at base year}

For countries included in groups $\mathrm{A}$ and $\mathrm{B}$, the number of $\mathrm{CF}$ patients and age distribution of the $\mathrm{CF}$ population for the base year were obtained using data registered in the latest year available of the ECFS Patient Registry.

For countries included in groups $\mathrm{C}$ and $\mathrm{D}$, the number of CF children and adults for the base year were estimated as follows. The number of CF patients in each country was calculated by multiplying its $\mathrm{CF}$ prevalence times the general population, as estimated by the Population Reference Bureau in 2009 [7]. CF prevalence estimates were those published by FARRELL [3] for EU countries; CF prevalence for Russian Federation was obtained from the recently established Russian CF Patient Registry [9], and this prevalence was also applied to Ukraine and Belarus. Because large variations in the percentage of adults in various European countries were previously reported [5], and were ascribed to differences in resource allocation to 
TABLE 1 Demographic characteristics and European Cystic Fibrosis Society (ECFS) Patient Registry participation in 34 European countries

\section{Country}

$\begin{array}{cc}\text { EU } & \text { Population } \\ \text { member } & 2009^{\#}[7]\end{array}$
2009\# [7]

GNI per
capita 2009

\$ [8]

Reporting data
to the ECFS
registry
2007-2010

Country registry coverage $\geqslant 85 \%$

\section{Longitudinal registry data $\geqslant 4$ years}

\section{CF prevalence Country per 10000 group for analysis}

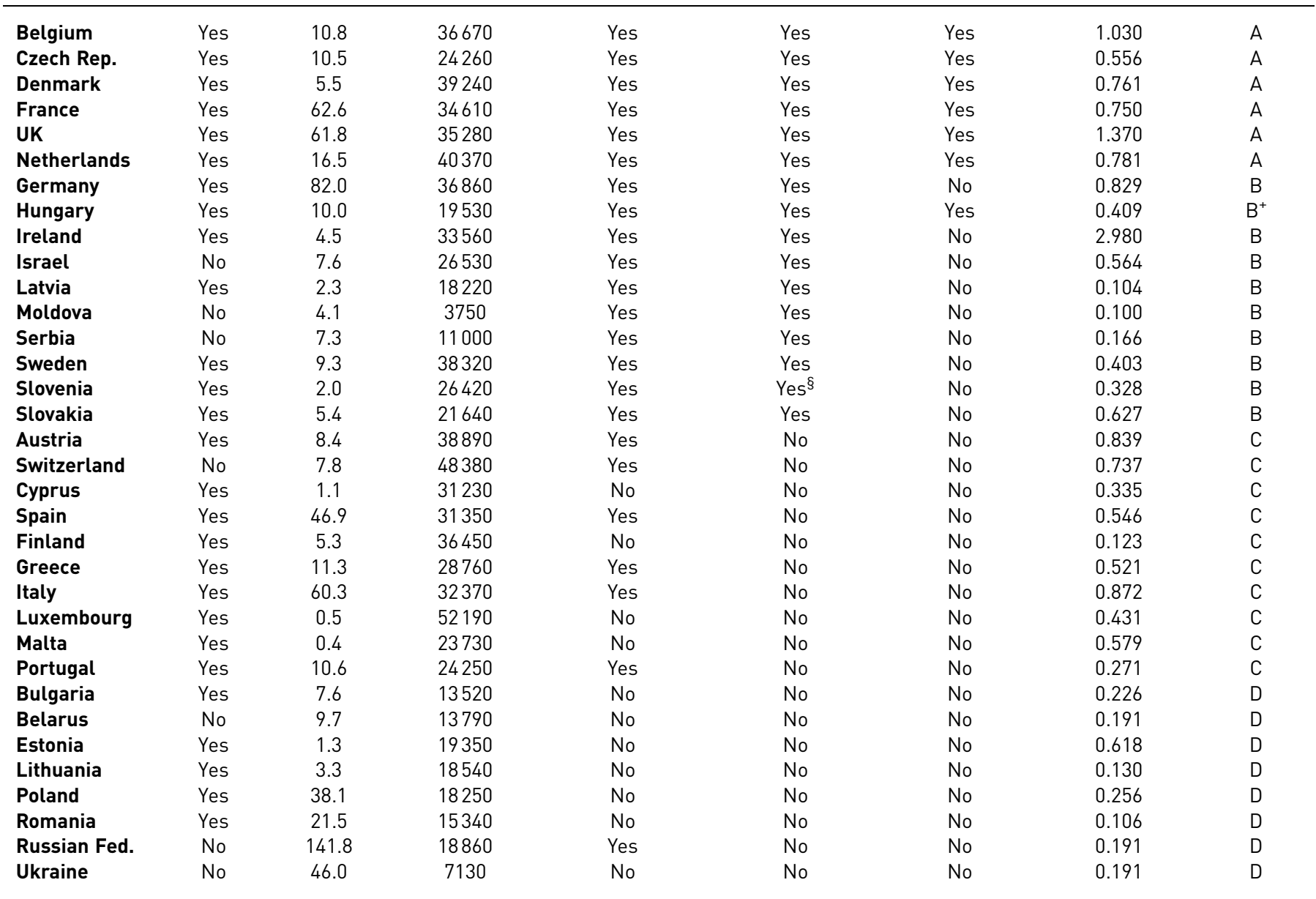

Country groups were defined as follows, group A: contributing data to the ECFS Patient Registry, coverage $\geqslant 85 \%$ of the cystic fibrosis (CF) population, longitudinal data linked at the patient level in the ECFS Patient Registry for at least 4 years. Group B: contributing data to the ECFS Patient Registry, coverage $\geqslant 85 \%$ of the CF population, longitudinal data for $<4$ years or no longitudinal data. Group C: not contributing data to the ECFS Patient Registry or coverage $<85 \%$ of the CF population and gross national income (GNI) per capita $\geqslant \$ 23000$. Group D: not contributing data to the ECFS Patient Registry or coverage $<85 \%$ of the CF population and GNI per capita $<\$ 23000$. " : in millions. ": estimates of CF prevalence in individual countries was taken from FARRELL [3], except for: Switzerland, where prevalence was based on the mean prevalence of the 27 European Union (EU) countries [3]; Moldova, Israel and Serbia, where prevalence was calculated using the number of CF patients reported to the ECFS registry and population of the country; Russian Federation, Belarus and Ukraine, where prevalence was reported by the Russian CF Patient Registry [9]. ${ }^{+}$: Hungary was included in group B because the number of deaths were not systematically reported to the ECFS Patient Registry between 2007 and 2010. ${ }^{\S}$ : Slovenia had coverage at 75\%. The GNI per capita was based on purchasing power parity in current international dollars (\$).

the healthcare system in EU versus non-EU countries [5], we used GNI per capita based on purchasing power parity (PPP) as an indicator for estimating the percentage of adults among CF patients.

Countries categorised in group C, which had GNIs per capita comparable to countries of group A, were applied a percentage of CF adults that was the weighted mean calculated for countries of group A ( $48.8 \%$ adults). Since data from the Russian CF Patient Registry suggested that the CF population in Russian Federation contained $25 \%$ of adult patients [9], this percentage of adults was used for group D countries with GNIs per capita ranging from $\$ 18000$ to $\$ 20000$, including Estonia, Lithuania, Poland and Russian Federation. Finally, for countries classified in group D with GNIs per capita $<\$ 17000$ (Bulgaria, Belarus, Romania and Ukraine), a 15\% adult rate was applied, based on published estimates [5]. 


\section{CF population forecasts for countries in groups $A$ and $B$}

For countries in groups $\mathrm{A}$ and $\mathrm{B}$, population forecasts (i.e. estimates that are considered to yield a realistic picture of the probable future development of a population [10]) were calculated by modelling evolution of registry cohorts in each country using the flow method. This method is based on calculation of the evolution of a known cohort (such as the CF population followed in a national registry) during a period of observation $[11,12]$. Entering, exiting and transition flows in a population of CF children and adults from year $t$ to year $t+1$ are shown in figure 1. Each year, exiting cases include deaths (which can occur in both the child and adult populations) and patients lost to follow-up, whereas entering cases include new referrals based on neonatal screening or clinical diagnosis in children and in adults, and re-tracking of patients previously lost to follow-up. Additionally, transition from child to adult population occurs in patients aged 18 years. Mean yearly flows were computed in the cohort over a period of time and were applied to the cohort to estimate its evolution across years, assuming that these flows remained unchanged during the estimation period.

Data obtained from the ECFS Patient Registry were used to calculate flows in each group A country. A minimum of 4 years of longitudinal data was considered necessary for calculating mean yearly flows in order to reduce year to year variations. A detailed explanation of the calculation of flow is provided in the online supplementary material. In each country in group A the mean yearly entering, exiting and transition flows over the observation period were computed and used to estimate the number of CF children and adults by 2025. Further, weighted (based on relative contribution of the country CF population to total CF population in countries of group A) mean flows obtained in these six countries were calculated and applied to the registry data of countries in group B to estimate their numbers of CF children and adults by 2025 .

\section{CF population projections for countries in groups $C$ and $D$}

For countries in groups $\mathrm{C}$ and $\mathrm{D}$, population projections (i.e. calculations that show the future development of a population when certain assumptions are made [10]) were calculated. The strategy for each country category is described below and summarised in table 2. For these two groups of countries, the flow method could not be used because of the absence of nationwide registry data. Future numbers of CF children and adults in each country were estimated under different scenarios.

For countries in group $\mathrm{C}$, in which the healthcare system was considered comparable to the healthcare system of countries in group A (on the basis of comparable GNIs per capita), it was assumed that their population dynamics were the 2010-2025 weighted mean growth rates of child and adult CF populations calculated in the group A countries.

Year $\mathrm{t} \quad$ Year $\mathrm{t}+1$

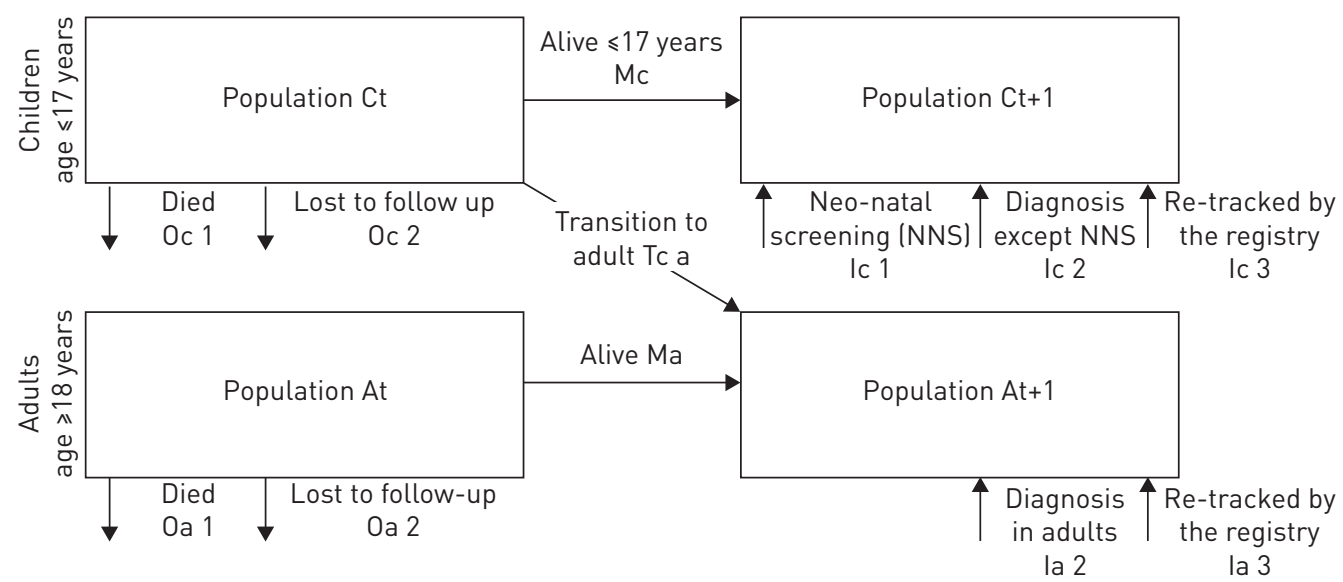

Exiting flows Transition flows Entering flows

FIGURE 1 The flow method. The evolution of a known registry cohort of cystic fibrosis (CF) children and adults from year $t$ to year $t+1$ can be modelled by calculating entering, exiting and transition flows in each population. In the child population, exiting flow are composed of children who died during the year (Oc1) and children lost to follow-up (exiting flow, Oc2). Entering flows are composed of new cases of CF, including CF cases diagnosed by neonatal screening (Ic1) and $\mathrm{CF}$ cases diagnosed later in childhood (Ic2); additionally children lost to follow-up during previous years may be re-tracked by the registry (Ic3). Transition flows include children remaining in the child population (Mc) and children growing into an adult (age $\geqslant 18$ years) (Tca). For the adult population, exiting flows are composed of adults who died during the year (Oa1) and adults lost to follow-up (Oa2); entering flows are composed of new cases of CF diagnosed in adults (Ia2), CF children growing into an adult (Tca), and previously lost to follow-up CF adults re-tracked by the registry (Ia3). CF adults remaining in the registry $(\mathrm{Ma})$ also contribute to the year $\mathrm{t}+1$ adult population. 
TABLE 2 Analyses strategy, according to country groups

\begin{tabular}{|c|c|c|c|c|c|}
\hline Group & Country & $\begin{array}{l}\text { GNI per } \\
\text { capita \$ }\end{array}$ & CF population & $\begin{array}{l}\text { Age composition at } \\
\text { base year }\end{array}$ & $\begin{array}{l}\text { Method used for estimating age } \\
\text { composition by year } 2025\end{array}$ \\
\hline A & $\begin{array}{l}\text { Belgium, Czech Republic } \\
\text { Denmark, France, UK, } \\
\text { the Netherlands }\end{array}$ & $24000-41000$ & Observed & Observed & $\begin{array}{l}\text { Forecast, flow method in each } \\
\text { country }\end{array}$ \\
\hline B & $\begin{array}{l}\text { Germany, Hungary, Ireland, } \\
\text { Israel, Latvia, Moldova, } \\
\text { Serbia, Sweden, Slovenia, } \\
\text { Slovakia }\end{array}$ & $3000-39000$ & Observed & Observed & $\begin{array}{l}\text { Forecast, flow method using the } \\
\text { weighted mean of flows calculated } \\
\text { for countries of group } A\end{array}$ \\
\hline C & $\begin{array}{c}\text { Austria, Switzerland, } \\
\text { Cyprus, Spain, Finland, } \\
\text { Greece, Italy, Luxembourg, } \\
\text { Malta, Portugal }\end{array}$ & $23000-53000$ & $\begin{array}{l}\text { Calculated using } \\
\text { general population data } \\
\text { and CF prevalence }\end{array}$ & $\begin{array}{l}\text { Estimated assuming } \\
\text { mean proportion of } \\
\text { adults observed in } \\
\text { countries of group } \\
\text { A: } 48.8 \% \text { of adults }\end{array}$ & $\begin{array}{l}\text { Projection, on the assumption of the } \\
\text { weighted mean growth rates of } \\
\text { group A countries: increase by } 20 \% \\
\text { in children and by } 78 \% \text { in adults }\end{array}$ \\
\hline \multicolumn{6}{|c|}{$\begin{array}{l}\text { Country groups were defined as follows, group A: contributing data to the ECFS Patient Registry, coverage } \geqslant 85 \% \text { of the cystic fibrosis (CF } \\
\text { population, longitudinal data linked at the patient level in the ECFS Patient Registry for at least } 4 \text { years. Group B: contributing data to the ECFS } \\
\text { Patient Registry, coverage } \geqslant 85 \% \text { of the CF population, longitudinal data for }<4 \text { years or no longitudinal data. Group C: not contributing data to } \\
\text { the ECFS Patient Registry or }<85 \% \text { coverage of the CF population and gross national income (GNI) per capita } \geqslant \$ 23000 \text {. Group D: no } \\
\text { contributing data to the ECFS Patient Registry or coverage }<85 \% \text { of the CF population and GNI per capita }<\$ 23000 \text {. The GNI per capita was } \\
\text { based on purchasing power parity in current international dollars (\$). }\end{array}$} \\
\hline
\end{tabular}

For countries in group D, future numbers of CF children and adults were computed under two different scenarios. In the first scenario (scenario 1) a population growth, corresponding to the weighted mean growth rates of child and adult CF populations calculated in countries from group A, was also considered. Since this scenario appeared unlikely to occur due to smaller numbers of adults and younger aged children (resulting in smaller rates of transition to adulthood), the age composition by 2025 was estimated assuming an increase by $40 \%$ in both children and adults (scenario 2). The latter scenario was based on the assumption that predicted increase in numbers of CF patients would be higher in children and lower in adults in group D countries compared with group A countries.

All analyses were performed using the SAS statistical software. (Statistical Analysis System, version 9.3; SAS Institute, Inc., Cary, NC, USA).

\section{Results}

Forecasts for children and adult CF patient numbers for countries in groups $A$ and $B$

Table 3 summarises the forecasts for the number of CF children and adults by 2025 for each country within groups A and B; detailed country-specific trends between 2010 and 2025 are provided in the online supplementary material. Using 2010 as the base year, the total number of CF patients in the countries from group A (Belgium, Czech Republic, Denmark, France, UK and the Netherlands) would increase by $19 \%, 35 \%$ and $50 \%$ by the years 2015,2020 and 2025 , respectively; the number of CF children would increase by $9 \%, 16 \%$ and $20 \%$ by the years 2015,2020 and 2025 , respectively; and the number of CF adults would increase by $28 \%, 54 \%$, and $78 \%$ by the years 2015,2020 and 2025 , respectively.

Forecasts for countries within group B (Germany, Hungary, Ireland, Israel, Latvia, Moldova, Serbia, Sweden, Slovenia and Slovakia) indicated that the total numbers of CF patients in this group of countries would increase by $47 \%$ by 2025 , corresponding to an increase of $22 \%$ in children and of $72 \%$ in adults. According to these analyses, the total number of CF patients will increase from 26995 patients in 2010 to 40194 patients (an increase of 2780 children and 10419 adults) by 2025 in these 16 countries (groups A and B), and adult patients will represent $60 \%$ of all CF patients by 2025 . Figure 2 shows predicted numbers of CF children and adults by 2025 in countries for groups A and B separately and for groups A and B combined.

Based on an average number of $250 \mathrm{CF}$ adults per CF centre, these forecasts suggest the need for a $75 \%$ increase in the number of adult CF centres by 2025 (55 adult CF centres in 2010 versus 96 adult CF centres in 2025) in these 16 countries. 
TABLE 3 Summary of the 2010-2025 cystic fibrosis population forecasts for countries in groups A and B

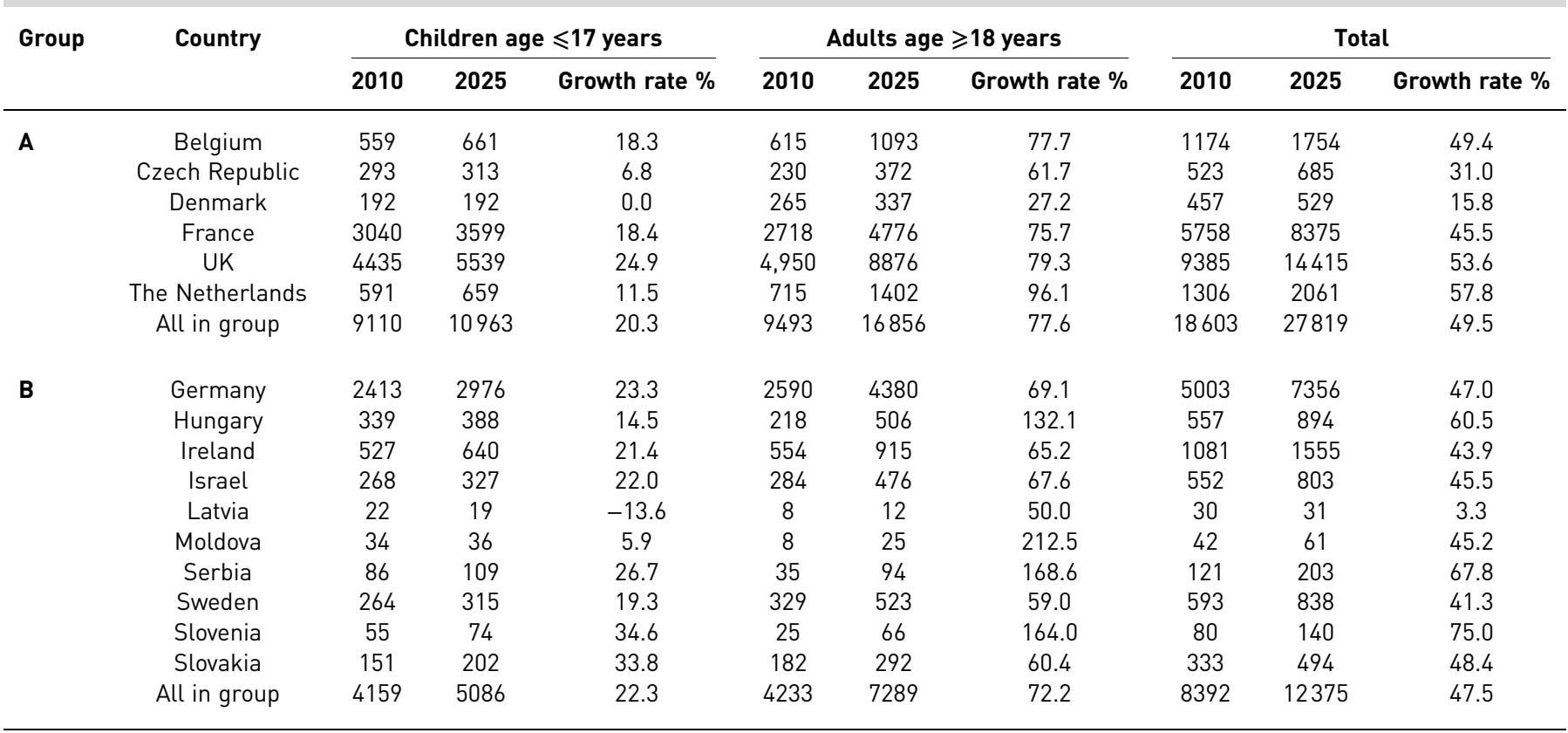

Projections of children and adult CF patient numbers for countries in groups $C$ and $D$

Individual projections for the 10 countries classified in group C (Austria, Switzerland, Cyprus, Spain, Finland, Greece, Italy, Luxemburg, Malta and Portugal), assuming the same population dynamics estimated for countries in group A (increase by $20 \%$ in children and by $78 \%$ in adults), are shown in table 4. These projections suggested that CF numbers in group C countries would increase by 4890 patients (an increase of 1035 children and 3855 adults) by 2025.

The number of CF children and adults in countries group from D (Bulgaria, Belarus, Estonia, Lithuania, Poland, Romania, Russian Federation and Ukraine) were estimated under two scenarios. Table 5 shows projections for countries in group $\mathrm{D}$, assuming the same population dynamics estimated for countries in group A (increase by $20 \%$ in children and by $78 \%$ in adults). According to this scenario, the CF population in countries from group D would increase by 1745 patients (an increase of 823 children and 922 adults). Because this first scenario appeared unlikely to occur (refer to Methods section), a second scenario assuming an increase by $40 \%$ in children and adults by 2025 was examined. According to this second scenario (table 6), the CF population in group D countries would increase by 2120 patients (an increase of 1648 children and 472 adults) by 2025 .

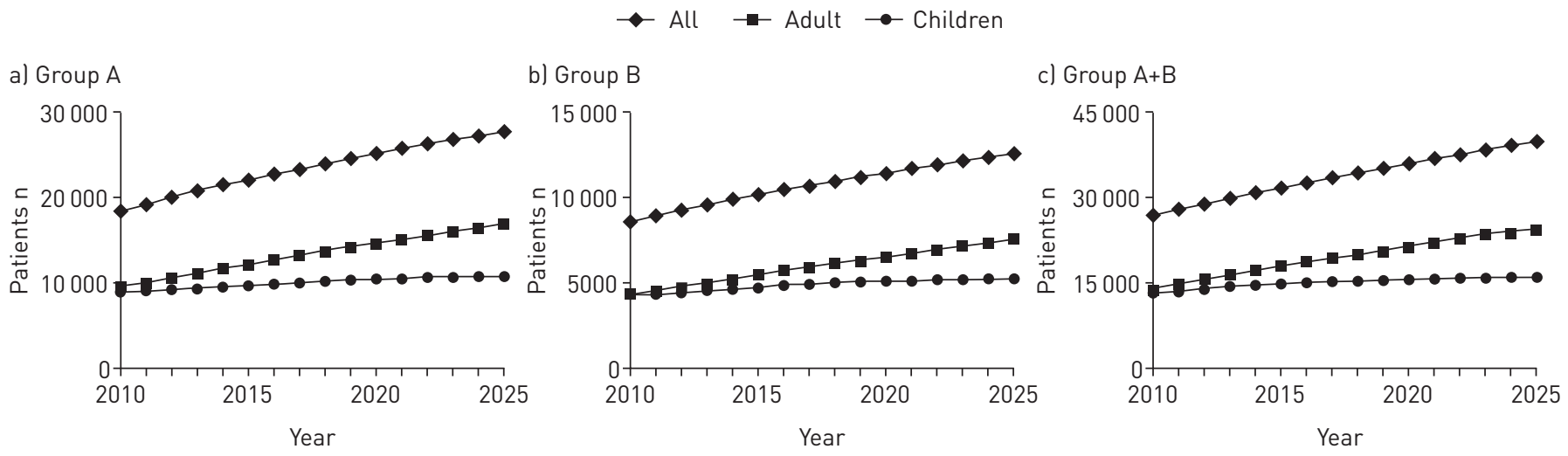

FIGURE 2 Forecasts of numbers of cystic fibrosis children and adults between 2010 and 2025 in countries classified in group A, group B and groups A+B. Group A: Belgium, Czech Republic, Denmark, France, UK and The Netherlands. Group B: Germany, Hungary, Ireland, Israel, Latvia, Moldova, Serbia, Sweden, Slovenia and Slovakia. 
TABLE 4 Summary of $2010-2025$ cystic fibrosis population projections for countries in group C

\begin{tabular}{|c|c|c|c|c|c|c|c|c|c|c|c|c|}
\hline \multirow[t]{2}{*}{ Country } & \multicolumn{4}{|c|}{ Children age $\leqslant 17$ years } & \multicolumn{4}{|c|}{ Adults age $\geqslant 18$ years } & \multicolumn{4}{|c|}{ Total } \\
\hline & 2010 & 2015 & 2020 & 2025 & 2010 & 2015 & 2020 & 2025 & 2010 & 2015 & 2020 & 2025 \\
\hline Austria & 361 & 393 & 419 & 433 & 344 & 440 & 530 & 612 & 705 & 833 & 949 & 1045 \\
\hline Cyprus & 19 & 21 & 22 & 23 & 18 & 23 & 28 & 32 & 37 & 44 & 50 & 55 \\
\hline Spain & 1311 & 1429 & 1521 & 1573 & 1250 & 1600 & 1925 & 2225 & 2561 & 3029 & 3446 & 3798 \\
\hline Finland & 33 & 36 & 38 & 40 & 32 & 41 & 49 & 57 & 65 & 77 & 87 & 97 \\
\hline Luxembourg & 11 & 12 & 13 & 13 & 11 & 14 & 17 & 20 & 22 & 26 & 30 & 33 \\
\hline Malta & 12 & 13 & 14 & 14 & 11 & 14 & 17 & 20 & 23 & 27 & 31 & 34 \\
\hline Portugal & 147 & 160 & 171 & 176 & 140 & 179 & 216 & 249 & 287 & 339 & 387 & 425 \\
\hline All in group & 5180 & 5645 & 6010 & 6215 & 4942 & 6326 & 7612 & 8797 & 10122 & 11971 & 13622 & 15012 \\
\hline
\end{tabular}

Assumptions on population dynamics based on observed dynamics of countries within group A: increase by $9 \%$ in children and by $28 \%$ in adults between 2010 and 2015; increase by $16 \%$ in children and by $54 \%$ in adults between 2010 and 2020 ; increase by $20 \%$ in children and by $78 \%$ in adults between 2010 and 2025 .

\begin{abstract}
Discussion
Forecasts for 2025 in 16 European countries, with well-established data collections, indicated that the number of CF patients will increase by approximately $50 \%$. The number of $\mathrm{CF}$ adults will increase by approximately $75 \%$, a finding that mostly results from the transition of children to adults, whereas the number of CF children will show a $20 \%$ increase. This trend also appeared realistic for 10 Western European countries (group C) with well-established healthcare systems, but in which the absence of a national registry did not allow to perform forecasts but only a projection. In eight Eastern European countries (group D) with less well-established healthcare systems, population projections suggested that an improvement in CF care would lead to a predominant increase in the number of CF children in the next decade, although the number of $\mathrm{CF}$ adults would also increase. The present population forecasts and projections should be useful for planning children and adult CF care in individual European countries.

To the best of our knowledge, this study represents the first attempt at estimating future numbers of $\mathrm{CF}$ children and adults. For countries that were classified in group A, the use of registry data allowed to forecast the number of CF patients by calculating flows entering and exiting the cohorts in each country. We evaluated the robustness of this approach by comparing our 2-year forecast for year 2012 in France with observed 2012 data in the French CF Registry [13]. In 2012, our data estimated a total number of 6177 CF patients ( 3153 children and 3024 adults) in France (online supplementary data); the 2012 French CF Registry registered 6145 CF patients (3099 children and 3046 adults) [13]. These findings indicated that our modelling approach was sensible for France over a short period of time, in which no major change in CF incidence and mortality occurred.
\end{abstract}

TABLE 5 Summary of 2010-2025 cystic fibrosis population projections for countries in group D according to scenario $1^{\#}$

\begin{tabular}{|c|c|c|c|c|c|c|c|c|c|c|c|c|}
\hline Country & \multicolumn{4}{|c|}{ Children age $\leqslant 17$ years } & \multicolumn{4}{|c|}{ Adults age $\geqslant 18$ years } & \multicolumn{4}{|c|}{ Total } \\
\hline Bulgaria & 146 & 159 & 169 & 175 & 26 & 33 & 40 & 46 & 172 & 192 & 209 & 221 \\
\hline Estonia & 60 & 65 & 70 & 72 & 20 & 26 & 31 & 36 & 80 & 91 & 101 & 108 \\
\hline Lithuania & 32 & 35 & 37 & 38 & 11 & 14 & 17 & 20 & 43 & 49 & 54 & 58 \\
\hline Poland & 731 & 797 & 848 & 877 & 244 & 312 & 376 & 434 & 975 & 1109 & 1224 & 1311 \\
\hline Ukraine & 747 & 814 & 867 & 896 & 132 & 169 & 203 & 235 & 879 & 983 & 1070 & 1131 \\
\hline All in group & 4123 & 4493 & 4783 & 4946 & 1181 & 1512 & 1818 & 2103 & 5304 & 6005 & 6601 & 7049 \\
\hline
\end{tabular}

\# : scenario 1 includes assumptions on population dynamics based on observed dynamics of countries of group A: increase by $9 \%$ in children and by $28 \%$ in adults between 2010 and 2015 ; increase by $16 \%$ in children and by $54 \%$ in adults between 2010 and 2020 ; and increase by $20 \%$ in children and by $78 \%$ in adults between 2010 and 2025. 
TABLE 6 Summary of $2010-2025$ cystic fibrosis population projections for countries in group D according to scenario $2^{\#}$

\begin{tabular}{|c|c|c|c|c|c|c|}
\hline Country & \multicolumn{2}{|c|}{ Children age $\leqslant 17$ years } & \multicolumn{2}{|c|}{ Adults age $\geqslant 18$ years } & \multicolumn{2}{|c|}{ Total } \\
\hline Bulgaria & 146 & 204 & 26 & 36 & 172 & 240 \\
\hline Estonia & 60 & 84 & 20 & 28 & 80 & 112 \\
\hline Lithuania & 32 & 45 & 11 & 15 & 43 & 60 \\
\hline Poland & 731 & 1023 & 244 & 342 & 975 & 1365 \\
\hline Ukraine & 747 & 1046 & 132 & 185 & 879 & 1231 \\
\hline All in group & 4123 & 5771 & 1181 & 1653 & 5304 & 7424 \\
\hline
\end{tabular}

\#: scenario 2 includes assumptions on population dynamics: increase of 40\% in children and adults between 2010 and 2025.

A limitation of the flow method is that entering and exiting flows could show yearly variations. For example, improvement in efficiency in patient referral to national registries could result in the identification of previously unreported CF cases, increasing the entering flow. The occurrence of a high rate of mortality in a specific year (e.g. due to an influenza epidemic) would increase the exiting flow, whereas underreporting of mortality could result in decreasing the exiting flow. We smoothed these potential variations by calculating mean flows for $4-8$ years (depending on data availability) in each country. Further, the flow method is based on the assumption that future flows remain stable as compared to mean past flows. This assumption is valid over a short period of time but may prove wrong over a longer period of time. Current knowledge suggests that future flows could evolve differently in the adults versus the child CF populations. Since CF patients who will become adults in the next 15 years are mostly already captured in registry populations, and since death is now rare among CF children in Western Europe countries [14], the most important unknown variable when estimating future numbers of adults is the mortality rate in adults. As longevity has consistently increased over the past 10 years [15], and may continue to increase with improvement in symptomatic care and the recent introduction of novel therapies targeting the cystic fibrosis transmembrane conductance regulator defect [16], our estimates of a $75 \%$ increase in the adult CF population may be considered conservative. By contrast, our estimates of a $20 \%$ increase in the child CF population could represent an overestimation if the incidence of CF decreases in the next decade, due to possible effects of systematic neonatal screening and/or carrier screening [17]. These considerations may even amplify the increase in the adult versus the child population described in the present analysis. Further, it is likely that CF is underdiagnosed in some of the Eastern Europe countries. The introduction of neonatal screening and availability of cost-effective genetic panels for the diagnosis of CF may increase the number of patients in the child age group and subsequently the number of adult patients.

This study also highlighted the importance of high-quality registry data to understand present and future CF epidemiology: country-specific flows could be calculated only in six (group A) countries with extensive registry coverage and longitudinal data. For 10 countries without longitudinal data (group B countries), forecasts were based on mean flows estimated in group A countries. Although we speculated that population dynamics of these two groups were comparable, this assumption could be more accurate for group B countries with high GNIs per capita in which the healthcare systems is comparable to group A countries, than for group B countries with lower GNIs. For countries without robust registry data, analyses had to rely on assumptions on current numbers of CF patients and current proportion of adults in each country. These assumptions might be associated with some degree of error. The use of GNIs per capita as an indicator for resource allocation to the healthcare system, which was associated with proportion of CF adults in a previous study [5], appeared as a reasonable, but questionable, approach. The \$23000 GNI per capita cut-off value was chosen because it discriminated Western European countries, in which there are well-established healthcare systems and Eastern European Countries with less well-established healthcare systems. Population growth dynamics for countries in groups $\mathrm{C}$ and $\mathrm{D}$ should be regarded as working hypotheses that will not replace establishment of a nationwide CF registry in each country. Finally, it was not possible to estimate age composition of CF cohorts for some countries (Armenia, Bosnia, Croatia, Georgia, Iceland and Turkey) for which limited data availability in the literature precluded reliable estimates of current CF epidemiology. Obtaining these data would be of interest, but the relatively small numbers of CF patients in these countries [5] will unlikely change our overall conclusions. 
The present study has modelled the impact of improved outcome on the CF population size and predicts a large increase in CF adults during the next decade in Western European countries. In the light of these expectations, it is important to adapt the healthcare system by providing sufficient allocation of resource and by establishing a strategy to develop adult CF care centres in Western European countries. It is also important to develop child and adult CF care centres in European countries with less well-established healthcare systems.

\section{Acknowledgements}

European Respiratory Society and the European Cystic Fibrosis Society (ECFS) Task Force members; Scott Bell (The Prince Charles Hospital, and the Queensland Children's Medical Research Institute, Brisbane, Australia), Francesco Blasi (Università degli Studi di Milano, IRCCS Fondazione Ospedale Maggiore Policlinico Cà Granda Milano, Milan, Italy), Pierre-Régis Burgel (Université Paris Descartes, Sorbonne Paris Cité, and Assistance publique-Hôpitaux de Paris, Paris, France), Carlo Castellani (Azienda Ospedaliera Universitaria Integrata, Verona, Italy), Birgit Dembski (Mukoviszidose eV, Berlin, Germany), Pavel Drevinek (Charles University and Motol University Hospital, Prague, Czech Republic), J. Stuart Elborn (Centre for Infection and Immunity, Queen's University, Belfast, UK), Harry Heijerman (Haga Teaching Hospital, The Hague, The Netherlands), Alastair Innes (Western General Hospital and Edinburgh University, Edinburgh, UK), Hanne Olesen (Aarhus University Hospital Skejby, Aarhus, Denmark), Anders Lindblad (University of Gothenburg and Queen Silvia Children's Hospital, Gothenburg, Sweden), Susan Madge (Royal Brompton Hospital, London, UK), Karleen De Rijcke (Cystic Fibrosis Europe, Belgium), Amparo Solé (Adult CF and Lung Transplant Unit, University Hospital la Fe, Valencia, Spain).

We would like to thank the country coordinators that provided national data to the ECFS Patient Registry: Thomas Frischer (Austria); Muriel Thomas (Belgium); Pavel Drevinek (Czech Republic); Hanne Vebert Olesen (Denmark); Lydie Lemonnier (France); Lutz Nährlich (Germany); Elpis Hatziagorou (Greece); Rita Ujhelyi (Hungary); Godfrey Fletcher (Ireland); Meir Mei-Zahav (Israel); Carla Colombo (Italy); Karina Mahlina (Latvia); Vincent Gulmans (Netherlands); Celeste Barreto (Portugal); Svetlana Sciuca (Republic of Moldova); Natasa Stojnic (Serbia); Hana Kayserova (Slovakia); Uroš Krivec (Slovenia); Carlos Vazquez-Cordero (Spain); Isabelle de Monestrol (Sweden); Andreas Jung (Switzerland); and Elaine Gunn (UK).

We would also like to thank all the cystic fibrosis patients throughout Europe for their willingness to participate in the ECFS Patient Registry.

\section{References}

O'Sullivan BP, Freedman SD. Cystic fibrosis. Lancet 2009; 373: 1891-1904.

Davis PB. Cystic fibrosis since 1938. Am J Respir Crit Care Med 2006; 173: 475-482.

Farrell PM. The prevalence of cystic fibrosis in the European Union. J Cyst Fibros 2008; 7: 450-453.

McCormick J, Mehta G, Olesen HV, et al. Comparative demographics of the European cystic fibrosis population: a cross-sectional database analysis. Lancet 2010; 375: 1007-1013.

5 Mehta G, Macek MJ, Mehta A, et al. Cystic fibrosis across Europe: EuroCareCF analysis of demographic data from 35 countries. J Cyst Fibros 2010; 9: Suppl. 2, S5-S21.

6 European Cystic Fibrosis Society Patient Registry. ECF Patient Registry Annual Data Report 2010. Karup, European Cystic Fibrosis Society, 2010. Available from: www.ecfs.eu/projects/ecfs-patient-registry/annual-reports

7 Population Reference Bureau. 2009 World Population Data Sheet. Washington, Population Reference Bureau, 2009. Available from: www.prb.org/Publications/Datasheets/2009/2009wpds.aspx

8 The World Bank. GNI per capita, PPP (current international \$) http://data.worldbank.org/indicator/NY.GNP. PCAP.PP.CD Date last accessed: Feb 24, 2015.

9 Krasovskiy S, Kashirskaya N, Kapranov N, et al. Establishment of a Russian cystic fibrosis patient registry. J Cyst Fibros 2014; 13: Suppl. 2, S124.

10 International Union for the Scientific Study of Population. Multilingual Demographic Dictionary. 2nd Edn. Liège, Ordina Editions, 1982.

11 Guillois P. Les projections nationales d'effectifs dans le premier et le second degré-méthodologie-résultats à long terme. Education et Formation 1983; 2: 85-92.

12 Thonstad T. Analysing and Projecting School Enrolment in Developing Countries: A Manual of Methodology. Paris, United Nations Educational Scientific and Cultural Organization, 1981.

13 French CF Registry. Annual Data Report 2012. Paris, Vaincre la Mucoviscidose and Ined, 2014. Available from: http://www.vaincrelamuco.org/sites/default/files/french_cf_registryannual_data_report_2012.pdf

14 Urquhart DS, Thia LP, Francis J, et al. Deaths in childhood from cystic fibrosis: 10-year analysis from two London specialist centres. Arch Dis Child 2013; 98: 123-127.

15 MacKenzie T, Gifford AH, Sabadosa KA, et al. Longevity of patients with cystic fibrosis in 2000 to 2010 and beyond: survival analysis of the cystic fibrosis foundation patient registry. Ann Intern Med 2014; 161: 233-241.

16 Ramsey BW, Davies J, McElvaney NG, et al. A CFTR potentiator in patients with cystic fibrosis and the G551D mutation. N Engl J Med 2011; 365: 1663-1672.

17 Castellani C, Picci L, Tamanini A, et al. Association between carrier screening and incidence of cystic fibrosis. JAMA 2009; 302: 2573-2579. 